\title{
ANTÔNIO, BENTO E DOMINGOS: PATERNIDADE NA ELITE FARROUPILHA (1835-1845)
}

\section{ANTÔNIO, BENTO AND DOMINGOS: FATHERHOOD AMONG THE FARROUPILHA'S ELITE (1835-1845)}

DOI: http//dx.doi.org/10.15448/2178-3748.2017.1.26760

\author{
Carla Adriana da Silva Barbosa \\ Doutora em História (UFRGS) \\ carlaasbarbosa@gmail.com
}

\begin{abstract}
RESUMO: Num contexto marcado pela guerra e preponderância das imagens masculinas, a figura paterna representava a segurança corporal e simbólica das famílias da elite farroupilha. Neste artigo, analiso as manifestações de paternidade nas correspondências pertencentes a este grupo, como as escolhas para a educação e o legado a ser herdado por seus filhos.
\end{abstract}

PALAVRAS-CHAVE: Paternidade; Rio Grande do Sul; Elite Farroupilha.

ABSTRACT: In a context marked by war and preponderance of male images, the paternal figure represented the corporal and symbolic security of the families of the farroupilha elite. In this article, I analyze the manifestations of paternity in the correspondences belonging to this group, as the choices for education and the legacy to be inherited by their children.

KEYWORDS: Fatherhood; Rio Grande do Sul; Farroupilha Elite.

No decorrer dos anos 1835 e 1845, eclodiu ao sul do Império Brasileiro um evento de proporções políticas, econômicas e sociais conhecido como Guerra dos Farrapos. Este confronto teve grandes consequências na vida privada dos lares sul-rio-grandenses, afastando muitos pais de seus filhos. O distanciamento entre parentes nos legou diversas correspondências, fornecendo um rico aporte de informações a respeito do cotidiano e da vida privada no Rio Grande do Sul. Dentre as famílias apartadas, encontravam-se muitas pertencentes à elite farroupilha ${ }^{1}$. Esta elite era um grupo pequeno formado por importantes famílias com um grande poder político, econômico e social dentro da região. Na maioria das

\footnotetext{
${ }^{1}$ Segundo Monteiro (2009), o termo elite se refere, de forma geral, e um tanto imprecisa, àqueles indivíduos pertencentes aos grupos melhores situados na estrutura social como um todo. Esse termo surgiu com as obras de Mosca e Pareto sobre as características elitistas da minoria que detinha o poder, foi radicalizado com a noção de classe dominante pelo marxismo, e adquiriu corpo com as proposições de Mills (1959) sobre os grupos no poder. Nos anos 1960, esse termo teve seu caráter monolítico contestado pelas pesquisas locais daqueles que defendiam a natureza pluralista das elites, como Dahl (1961) e Putnam (1976).
} 
vezes, estas famílias apresentavam vínculos entre si, tanto familiares, quanto políticos e econômicos.

Neste artigo, analiso as cartas trocadas pelos farrapos Antônio Vicente da Fontoura, Bento Gonçalves da Silva e Domingos José de Almeida e alguns familiares. A escolha por pelos três personagens não se deu apenas porque estes pertenciam à categoria acima citada, mas também por estarem diretamente envolvidos (como líderes) no conflito que dividiu a província por dez anos. O conflito e a distância criaram a necessidade de que as decisões que envolviam os destinos da família, a educação dos filhos e a administração dos bens, deixassem de ser feitas em conversas - às quais o historiador nunca teria acesso - e passasse a ser feita pelas inúmeras missivas trocadas por estas famílias ${ }^{2}$.

A partir do exame destas cartas, pode-se afirmar que a família era a força motriz das decisões deste grupo, sendo ainda o referencial nas ações e posições de seus membros. Estes núcleos familiares se apresentavam com uma forte hierarquia, principalmente em relação à autoridade masculina e paterna. Porém, não se tratava de um poder absoluto do "patriarcaindivíduo", mas sim do poder da família (FREYRE, apud. BRÜGGER, 2000, p 76.). Para a tradição cristão-católica no Brasil, desde o período colonial, a família procedia como instituição social, em que as estirpes proprietárias e administradoras de seus negócios foram, predominantemente, a forma de organização econômica no século XIX (KUZNESOF, 1989, pp. 37-63). Esta posição da família como uma instituição econômica era legitimada pela legislação que regulamentava as heranças e também pela legislação comercial e familiar (ORDENAÇÕES FILIPINAS. Livro 4. Tit. 80-107). Seu poder era legitimado por diversas convenções e códigos culturais sobre os papéis exercidos pelas filhas e filhos, pelas esposas e mães e até mesmo pelos maridos e pais. A vida de cada um dos integrantes destes núcleos familiares não era pensada em função apenas de seus interesses, mas também como parte de uma unidade familiar, onde todos deveriam saber seus lugares e funções.

Controle, influência e poder eram parte das expectativas que a sociedade sul-riograndense do século XIX desenvolveu a respeito dos homens que pertenciam ao grupo da elite e isso não foi diferente à elite farroupilha. $\mathrm{O}$ status de uma pessoa dizia respeito à posição que ela ocupava em alguma dimensão ou conjunto de dimensões sociais. Elas eram

\footnotetext{
${ }^{2}$ As correspondências entre Bento Gonçalves da Silva, seus irmãos e seu pai Joaquim foram trocadas no período que decorre aos anos de 1806-1819. Mesmo não sendo o período enfocado por este trabalho (1835-1845), acreditamos que estas cartas nos mostram que houve a transmissão de algumas formas e ideais de comportamento desta geração para a geração posterior. No número de 71, escritas entre 03 de Fevereiro de 1836 a 27 de Dezembro de 1841. As correspondências encontradas nos AAHRS apresentam que Domingos escreveu 64 cartas à sua esposa Bernardina, enquanto esta lhe enviou 07. As cartas escritas por Antônio Vicente da Fontoura à sua esposa Clarinda são em número de 310, escritas entre $1^{\circ}$ de Janeiro de 1844 a 22 de Março de 1845. Contudo, não encontramos cartas enviadas pela mesma.
} 
definidas socialmente e em momentos distintos e considerados relevantes. Os recursos possuídos poderiam exercer, de forma mais eficaz, o controle sobre alguém, tanto de forma física, como pela posse de bens materiais e/ou conhecimentos; além de outras habilidades específicas. Quanto mais recursos um indivíduo tinha, maiores as chances de sucesso no seu exercício de poder.

A família e seu poder não se restringiam apenas a estreitos laços de consanguinidade ou parentescos afins ou políticos, seus limites dependiam muito das relações estabelecidas de forma intrafamiliar. Deveria haver respeito e concordância com as hierarquias e posições internas familiares, assim como com os papéis de gênero, mas nem por isso deixavam de existir conflitos e tensões, que deveriam ser tratados para que suas estruturas fossem preservadas. Assim, ela era dinâmica; seus membros tinham participação ativa e possuíam certos poderes de escolha, além de fazerem parte de uma intrincada rede de significações sociais, como ser mulher e ser homem.

As construções sociais dadas às categorias de mulher e homem, também se firmavam nas constituições dos papéis familiares (marido/esposa, pai/mãe, filho/filha). Segundo Bourdieu:

(...) a posição de um determinado agente no espaço social pode assim ser definida pela posição que ele ocupa em diversos campos, quer dizer, na distribuição dos poderes que atuam em cada um deles, seja, sobretudo, o capital econômico - nas suas diferentes espécies - , o capital cultural e o capital social e também o capital simbólico, geralmente chamado prestígio, reputação, fama etc. que é a forma percebida e reconhecida como legítima das diferentes espécies de capital (BOURDIEU, 2007, p.134-135).

Ao analisar estas atribuições, e as concepções acerca delas, é necessário entender o quanto elas foram influenciados por questões socioeconômicas e culturais, além da questão temporal. Conforme Lévi-Strauss, em todas as sociedades humanas, o aparecimento de uma família tem como condição a prévia existência de duas outras dispostas a fornecer respectivamente um homem e uma mulher, de cujo casamento nascerá uma terceira, e assim por diante indefinidamente (BURGUIÈRE, 1996, p. 08).

Mas, antes de começar o exame das imputações dos pais nestas famílias, mostrarei um pouco sobre a vida destes sujeitos que participaram ativamente da Guerra dos Farrapos. Começarei por Antônio Vicente da Fontoura nascido a oito de junho de 1807, na vila de Rio Pardo. Era filho do agrimensor Euzébio Manoel Antonio, natural de Portugal e de Vicência Cândida da Fontoura, natural de Rio Pardo. Foi casado com Clarinda Francisca Porto, filha de importante comerciante na vila de Cachoeira e assim como seu sogro, atuou no comércio, 
além de ter se envolvido na vida política da região e da província. Ao longo de sua vida matrimonial teve quatorze filhos: Antonio Eusébio, José Propício, Afonso Borges, Francisco de Paula, Bento, João Propicio, Tito Castilhos da Fontoura, Clarinda Amélia, Josepha Leopoldina, Gabriela Benta, Maria Egypcia, Vicencia Cândida, Antonia Francisca, Luzia Sophia (BARBOSA, 2009, p. 41-43).

Domingos José de Almeida era natural de Minas Gerais, nascido a nove de julho de 1797, filho do moleiro Domingos José de Almeida e Silva, natural de Portugal e de Escolástica Maria de Abreu, natural de Minas Gerais. Veio à Província do Rio Grande, em 1819, a fim de comprar tropas de muares na vila de São Francisco de Paula e por aqui permaneceu. Foi casado com Bernardina Barcellos de Almeida, filha de uma abastada família de Pelotas. Ao longo da vida dedicou-se ao comércio, à política e à imprensa. Com sua esposa, tiveram 13 filhos: Domingos (I) ${ }^{3}$, Domingos (II) ${ }^{4}$, Bernardino Bráulio, Luiz Felipe, Custódia Margarida, Maria Izabel, Junius Bruto Cássio, Epaminondas, Aristides, Abrilina Decimanona Caçapavana, Maria Carlota, Pelópidas Bagelino, Epaminondas Piratinino (BARBOSA, 2009, p. 38-40).

Bento Gonçalves da Silva Bento nasceu na freguesia do Senhor Bom Jesus do Triunfo, a 23 de setembro de 1788, era filho do capitão de ordenanças Joaquim Gonçalves da Silva, natural de Portugal e de Perpétua da Costa Meireles, natural da freguesia de Viamão. Empregou grande parte de sua vida às campanhas militares e atuou como criador de gado e político na Província do Rio Grande do Sul. Foi casado com Caetana Garcia da Silva, filha de um abastado criador de gado e comerciante uruguaio. Bento e Caetana tiveram oito filhos: Perpétua Justa, Joaquim, Bento Filho, Caetano, Leão, Marco Antônio, Maria Angélica e Ana Joaquina (BARBOSA, 2009, p. 40-41).

\section{Chegando à paternidade}

Comecemos com a ideia fundamental de que o pai era responsável pela existência física de seus filhos. Essa vida transmitida pelos pais, bem como as realizações materiais atribuíveis às gerações precedentes, eram tidas por graças ou dons, que tinham como contrapartida um sentimento de gratidão por parte dos filhos, ou "dívidas", das quais nada do que fizessem ao longo de sua existência permitiria ficarem isentos.

O pai não fazia apenas o papel de genitor - pai biológico -, era também pater - o pai social. Assim, o pai/genitor/pater não era apenas encarregado da vida de seus filhos, ele

\footnotetext{
${ }^{3}$ Nascido em 06/09/1825 e falecido em 22/06/1826.

${ }^{4}$ Nascido em 16/10/1826 e falecido em 17/02/1827.
} 
também era importante na sua manutenção. Domingos José de Almeida ao perder um dos seus filhos, encontrou as seguintes palavras de um amigo:

Com sentimento recebi a carta de V.S. de 2 do corrente, na que me participa o golpe que sofreu com a perda de seu filho mais velho, cujo sentimento acompanho a V.S. e a minha Senhora, sua esposa: não duvido que são acontecimentos difíceis de sobrelevar; por mim passou a perda dos dois mais velhos que experimentei, pouco me faltou para perder o juízo (ANAIS DO ARQUIVO HISTÓRICO DO RIO GRANDE DO SUL, 1981, p.232).

Mas as responsabilidades de um pai iam além da pura existência física dos filhos. A essa deveriam ser atribuídas outras questões, que envolviam uma demanda socioeconômica e cultural. A guerra dos farrapos foi um meio desses pais da elite farroupilha, que se sentiam desfavorecidos e ameaçados política e economicamente pelo poder central, garantirem um "futuro" para seus filhos, mesmo tendo que sofrer toda a sorte de desventuras e até arriscar a própria vida. Domingos escreveu a Bernardina:

Não obstante porém o justo azedume que me acompanha, resolvido estou a cerrar os olhos a tudo e redobrar de esforços para que a Província seja arrancada do abismo que a ameaça: nela tenho a ti e a sete filhos, e isto basta para que lhe deseje todas as venturas (ANAIS DO ARQUIVO HISTÓRICO DO RIO GRANDE DO SUL, 1978, p. 158-159).

Em outra carta, Domingos lhe diz o seguinte:

Sei, que mulher e filhos, e o estado pouco feliz de nossa casa, me deveria subtrair dessa comissão; mas a obrigação de coadjuvar com todas as minhas forças para o bem da Província, e particularmente de ti e desses mesmos filhos, me forçaram a uma empresa cheia de espinhos e de dificuldades: se algum sinistro não cogitado me roubar para sempre da minha família, o que não espero, o exemplo de servir à Pátria; que deixo a nossos filhos, é o mais brilhante legado que lhes posso doar: e esta única lembrança me consola, quando pondero na nossa separação, etc., etc... (ANAIS DO ARQUIVO HISTÓRICO DO RIO GRANDE DO SUL, 1978, p. 168-171).

Domingos, em trecho de outra correspondência lembra: “(...) e hoje se proclamou nesta a independência deste Estado, pelo que me congratulo contigo e com nossos filhos para quem trabalho" (ANAIS DO ARQUIVO HISTÓRICO DO RIO GRANDE DO SUL, 1978, p. 182-183). Da mesma maneira que Domingos José de Almeida, Antônio Vicente da Fontoura via a guerra também como um propósito familiar e para a garantia do futuro dos filhos e escreveu à esposa Clarinda: 
Quando eles (seus filhos) deixarem o teto paterno, quando entrarem no grande mundo, o velo do seu rosto viril não será crestado pelo afogueado calor da vergonha ao ouvir falar de seus maiores. Eles não contarão o ouro herdado, mas poderão referir com uma terna emoção os nossos infortúnios. Suas faces tomarão nesse instante o augusto colorido da modéstia e não do pejo (DIÁRIO DE ANTÔNIO VICENTE DA FONTOURA, 1984, p. 60).

Contudo, a guerra também foi um bom negócio para alguns dos estancieiros-militares, os quais ampliaram seus rebanhos, e eventualmente, açambarcavam mais terras para suas propriedades (GUAZZELLI, 1998, p.105) e, assim, mais uma garantia de bens materiais a serem herdados. Ela ainda trazia a possibilidade de prestígio e o "nome" poderia ser tão importante como um dote. O renome poderia ser adquirido pelos grandes feitos e pelo acúmulo de um cabedal militar e pessoal muito importante na composição não somente do papel de pai, mas também de um chefe farroupilha. A constituição de suas qualidades, tanto na guerra quanto nos negócios e na vida pessoal, eram fundamentais para a "nobreza" do nome que seria repassado aos filhos e também aos netos e suas ações poderiam resultar tanto de uma forma positiva quanto negativa no futuro dos filhos. Como lembra Bento Gonçalves em trecho de um manifesto impresso:

A execração de nossos filhos cairá sobre nossas cinzas se por nossa desmoralização e incúria lhe transmitirmos este sagrado depósito desfalcado e corrompido, e suas bênçãos nos acompanharão ao sepulcro se lhes deixarmos exemplos de virtudes e patriotismo (COLETÂNEA DE DOCUMENTOS DE BENTO GONÇALVES DA SILVA - 1835/1845, 1985, p. 268-274).

A manutenção de sua posição dependia, deste modo, também de uma reprodução do seu capital simbólico através da produção de herdeiros (masculinos ou femininos) capazes de perpetuar a herança do núcleo familiar e obter aliados prestigiados. Em outras palavras, assegurar o futuro dos filhos, orientar seu futuro, eram preocupações de um jogo social que tinha por finalidade ampliar as oportunidades dos indivíduos e preservar as dos próximos e dependentes. Não era à toa que o hábito de atribuir dotes ou antecipar bens se associava estreitamente às estratégias de aliança e de transferência de bens. Quando os filhos passavam por dificuldades financeiras, os pais ajudavam no pagamento de dívidas, muitas vezes doando a parte que caberia na partilha do espólio antes de sua morte.

Era fundamental aos filhos que estes recebessem doações ou heranças materiais ou simbólicas de seus pais, contudo, cabia aos primeiros a manutenção e até mesmo uma tentativa de superação do nome "paterno". Competia aos pais também prepararem sua prole para as adversidades na tentativa de fortalecimento do caráter. Em carta à sua esposa 
Clarinda, Antônio Vicente da Fontoura lembrava a importância da educação que receberam de seus pais:

(...) olhando para minhas mãos, não me lembrasse logo das tuas que, por causa do trabalho, já do forno, já da plantação com que vais ajudando a vestir e a sustentar nossos filhinhos, devem estar não só morenas, como pisadas do grosseiro serviço a que não eram acostumadas. Graças porém aos nosso pais que, não nos educando com excessivo efeminado luxo, souberam prevenir estes revezes que nos preparava a sorte! Parece mesmo, minha querida, que te antecipava a serviços tão duros (...) (DIÁRIO DE ANTÔNIO VICENTE DA FONTOURA, 1984, p. 33-34).

Ainda em outra carta de Fontoura à sua mulher, ele falou sobre a importância das adversidades na formação do caráter dos filhos:

Temos visto, minha Clarinda, desaparecer a fortuna de que éramos senhores antes da revolução; temos mesmo, no decurso dela, tragado o cálice da amargura por muitas vezes, porém diremos um dia: -Perdemos, sofremos, mas aprendemos. Nossos filhinhos então poderão sair mais amestrados na carreira da vida (DIÁRIO DE ANTÔNIO VICENTE DA FONTOURA, 1984, p. 29).

Um bom caráter estava entre as qualidades pessoais que compunham a honra de uma pessoa e, para isso, nenhum dos homens que pertencia à elite farroupilha queria ter seu nome ligado a adjetivos como "facinoroso", "covarde", "maricas", "maldoso", "perverso", "assassino" ou "ladrão". A manutenção de um bom nome, que estaria ligado aos filhos, foi um dos motivos que levou Bento Gonçalves da Silva ao duelo com Onofre Pires (ROSA, 1935, p. 113-116). A troca de correspondências entre os dois nos aponta isso. Bento Gonçalves escreveu:

Ilmo. Sr. Coronel Onofre Pires da Silveira Canto. Havendo chegado ao meu conhecimento que V.S ${ }^{a}$. em princípios do corrente mês em presença de vários indivíduos do Exército, quando vinha este em marcha, avançara proposições ofensivas a minha honra e ousara até chamar-me de ladrão, sufocando os impulsos de meu coração e aquele brio que em minha longa carreira militar guiara sempre minhas ações por amor de mina posição e mais que tudo da crise em que se acha este país que me é tão caro, sufocando, digo, aquele ardor com que em todos os tempos busquei o desagravo de minha honra, recorri aos meios legais, únicos exeqüíveis nas presentes circunstâncias; como porém sua posição de deputado o põe a coberto desse meio e deva eu em tal caso lançar mão do que me resta como um homem de honra, quisera que deve caracterizar um homem na posição de V. $S^{a}$. houvesse de dizer-me com urgência por escrito se é verdadeiro ou falso o que a respeito se me informou. Deixo de fazer a V.S ${ }^{\mathrm{a}}$. quaisquer reflexões a respeito. V.S $S^{a}$ as deve perfeitamente compreender (ROSA, 1935, p.113-116). 
Onofre Pires respondeu da seguinte maneira:

Cidadão General Bento Gonçalves da Silva. Ladrão de fortuna, ladrão da vida, ladrão da honra e ladrão da liberdade é o brado ingente que contra vós levanta a Nação Rio-Grandense, ao qual já sabeis que junto a minha convicção não pela a geral execração de que sois credor, o que lamento, mas sim pelos os documentos justificativos que conservo. Não deveis pois, Sr. general, ter em dúvida a conversa que a respeito tive, quando dela vos impôs tão prontamente esse correio tão vosso... Deixai de afligir-vos por haverdes esgotado os meios legais em desafronta dessa honra, como dizeis; minha posição não tolhe que façais a escolha do mais conveniente para o que sempre me encontrareis. Fica assim contestada vossa carta de ontem (COLETÂNEA DE DOCUMENTOS DE BENTO GONÇALVES DA SILVA - 1835/1854, 1985, p. 245).

O que aconteceu depois foi que Bento Gonçalves em desagravo de sua honra desafiou Onofre Pires para se baterem em um duelo. O resultado foi que o coronel Onofre Pires teve dois ferimentos pelos quais morreu dias depois. Já Bento Gonçalves foi intimado à prisão e, mais tarde, solto por "obrar como homem de verdadeiros sentimentos de honra" (COLETÂNEA DE DOCUMENTOS DE BENTO GONÇALVES DA SILVA - 1835/1854, 1985 , p. $245-246)^{5}$.

Não foi somente Bento Gonçalves que teve problemas relacionados à sua honra, Domingos José de Almeida também viu seu nome ameaçado:

Ilmo. Sr. Tenente-coronel Manuel de Macedo Brum. Chegando a meu conhecimento haver V. Sa . gravemente ofendido minha reputação para melhor capturar benévola amizade dos inimigos da causa rio-grandense com quem convive, lhe dirijo a presente para rogar-lhe que, a não querer passar por infame caluniador, no seu regresso venha munido de documentos para provar onde existe a estância que possuo com gados roubados desta, qual a marca deles e quem seu administrador ou capataz. Cumpre mais que traga também documentos para provar que não foram vendidos por meu cunhado João Rodrigues Barcellos e por minha ordem trinta e cinco escravos de minha propriedade a Manuel Gonçalves da Costa, negociante dessa praça, e se tenho ou não outros aí alugados. Isto se faz indispensável para V.Sa . mostrar veracidade do que asseverou; e que não tenho aplicado o produto daqueles e o aluguel destes para as despesas do estado, a quem sirvo sem o interesse de um real, e a quem me ufano de ter sacrificado meus serviços, minha fortuna e a fortuna de meus credores. (...) e com soberba, desafio a

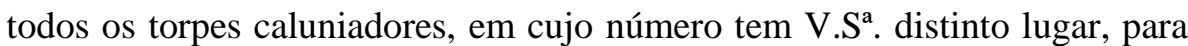
provarem o contrário (ANAIS DO ARQUIVO HISTÓRICO DO RIO GRANDE DO SUL, 1978, p.357-358).

Mas, ao contrário de Bento Gonçalves, Almeida preferiu recorrer à imprensa para defender sua honra. No jornal $O$ Povo do dia 26 de dezembro de 1838, na sessão

\footnotetext{
${ }^{5}$ Escrito por alguém que se intitulou: "um amigo dos homens de sentimentos de honra"
} 
Correspondências, Almeida se defendeu de incriminações feitas pelo Sr. Manoel Martins

Barrozo, acusações essas de prevaricação e fraudes. Domingos José de Almeida respondeu:

Há pessoas a quem falta a capacidade necessária para saírem por qualquer meio honesto, e decente, da obscuridade, e desprezo, a que a natureza parece hace-los condenado, e não querendo resignar-se a sua sorte, lançam mão dos recursos ainda mais torpes para ver se conseguem despertar, e atrair a atenção do público (O Povo. Piratini. 26/12/ 1838, n.31, Vol. I, pp.3-4).

E continuou sua defesa:

Mas em vez de convencer-se de seu erro, e de minhas intenções muda de rumo, o propõem-se mostrar minhas prevaricações, e fraudes. Cumpre-me confessá-lo com a ingenuidade que me é própria, tenho prevaricado, e tenho cometido fraudes; prevaricado em consentir no Tesouro o Sr. Barrozo, a despeito do erro impassível que cometeu no modelo enviado as Comissões do troco do cobre, para transtornar talvez aquela tão útil, quão necessária operação, mas que por felicidade foi desprezado pelas mesmas Comissões, a exceção de uma: prevaricado quando não o expulsei do mesmo Tesouro por escriturar sem ordem que para isso o autorizasse a conta de Pedro Mevielle, que sendo em moeda corrente, e ainda não legalizada, classificou parte nessa moeda, e parte em prata: a fraude em anuir que do empréstimo contraído para escassamente minorar as precisões do Exército, as escoasse para o $\mathrm{Sr}$. Barrozo a quantia descrita no seu jornal n.16; fraude, quando ainda permiti a extração de barricas de farinha para pagamento de seus vencimentos, estando aliás em circunstâncias de deixar essas bagatelas para algum mais...

Porém, Sr. Redator, tudo isso era mister, e estava no plano de alarmar muita gente, que com razão se julga credora de quinhão igual se não maior, e ao mesmo tempo arredar recursos criados, afim de paralisar os movimentos do Exército, e acarretar sobre o Governo a odiosidade, e descrédito que lhe é mister, para montar nossa nascente associação política etc., etc., etc. Tendo dado a satisfação devida ao público a quem em extremo respeito, e ao $\mathrm{Sr}$. Barrozo a consideração de que é credor, protesta não mais incomodar-lhe a respeito (O Povo. Piratini. 26/12/ 1838, n.31, Vol. I, pp.3-4).

Devemos lembrar que a honra da pessoa era avaliada pelo grupo, mas também era algo que só tinha sentido quando internalizada. O grupo, da mesma forma que a pessoa, deveria reconhecer que ele próprio internalizava o sentimento de honra. Ela poderia ser entendida como precedência, respeitabilidade, consideração e distinção. Segundo Monsma:

A honra hierárquica é uma forma do capital simbólico. (...). A honra hierárquica afere o valor social relativo de um homem, seu valor para sua família, para parceiros de trocas, para sua comunidade, para seu país. Dado o direito básico ao respeito, os homens acumulam o capital simbólico da honra por meio da conjunção de, por um lado, privilégio, riqueza e poder e, por outro, atos honrados, que demonstram a internalização do sentido de honra e muitas vezes são facilitados pela posse de recursos e poder. Além de ser valorizada por si só, a honra traz outros benefícios. Um homem de honra tem tanto os recursos como a fibra moral necessários para assumir e cumprir compromissos, o que significava que ele é um parceiro valioso e confiável 
para diversos tipos de trocas. (...). O capital simbólico, difícil de aferir e validado pela opinião dos outros, pode evaporar rapidamente. Na maioria dos grupos que enfatiza a honra, aqueles que não defendem sua honra contra desafios a perdem. Nesses grupos, os homens são bastante sensíveis a ofensas, e só podem desconsiderar um desafio se provir de alguém tão inferior que não merece resposta. Em geral, a honra é mais importante nos contextos onde lealdades pessoais são mais importantes para a segurança e o sucesso (MONSMA, 2008).

A honra também era determinada pelo controle que se tinha sobre a família. A construção e cuidados com o caráter dos filhos e as virtudes das filhas era algo de vital importância ao núcleo familiar. Mas este controle era mantido pelo respeito e não pela violência. Quem conseguia "comandar" esposa e filhos era visto como alguém que teria sucesso também no domínio dos negócios. Desta forma, a vida familiar podia ser um reflexo para a vida pública, sendo as ações privadas tão importantes como as externas.

Essa autoridade sobre os filhos podia se dar de diferentes formas, mas principalmente como dever, obrigação para com o pai, genitor de sua vida e dos bens materiais e simbólicos que seriam futuramente herdados. Essa troca de responsabilidades entre pais e filhos, ainda tinha o respaldo das Ordenações Filipinas que não tratavam a propriedade como um privilégio e sim como um encargo, limitando a liberdade do uso dos bens e declarando que os pais deveriam conservar e aumentar seu patrimônio em benefício dos seus herdeiros, sem dissipar suas possessões (ORDENAÇÕES FILIPINAS, LIV.4, TIT.103 E 107).

Entre os bens a serem doados pelos homens da elite farroupilha aos seus filhos estava a instrução desses e mesmo em meio à guerra, havia tempo para a preocupação com sua aprendizagem. A educação neste período tendia a socializar as pessoas de acordo com modelos funcionais para uma determinada sociedade (ANDRADE ET AL, 2012, p.178).E no caso destes farroupilhas, era uma possibilidade de ampliar as possibilidades de trabalho aos seus filhos, já que nem todos acabariam por ser o herdeiro sucessor proprietário de terras ou dos negócios da família. Os outros teriam que se aventurar em profissões como burocratas e bacharéis (VARGAS, 2011, p.10).

Domingos de Almeida, que sempre teve a educação como uma de suas metas e destacou parte de seu tempo como Ministro do Interior na criação das denominadas escolas de primeiras letras para a Província, demonstrou em algumas cartas grande preocupação com a instrução de seus filhos:

Meu querido Bernardino.

Tuas cartas de 14 e 22 do corrente me têm enchido de vivo prazer, por saber que ao fazê-las ficava de saúde: porém a falta de ortografia que nelas noto, a repetição de palavras e oração incorreta me faz pensar ou que pouco atendes

Oficina do Historiador, Porto Alegre, EDIPUCRS, v. 10, n. 1, jan./jun. 2017, 
a teus mestres, ou que estes pouco têm se aplicado a tua instrução. $O$ talhe da tua letra não é mau, mas ainda muito acanhado; pelo que seria bom que escrevesses algum tempo letras grandes com o braço no ar. A par disto não te descuides da gramática nacional, sem a qual nunca escreverás com acerto. Se aí houver quem ensine francês aplica-te ao menos na tradução dessa língua, não desprezando a aritmética. Isto mesmo recomenda a Luís. Teu pai e amigo que todo o bem te deseja (ANAIS DO ARQUIVO HISTÓRICO DO RIO GRANDE DO SUL, 1978, p. 341) ${ }^{6}$.

Em algumas missivas encontrou-se pedidos a sua esposa Bernardina que ficasse atenta aos ensinamentos prestados aos mesmos. Domingos deixou bem claro o quanto isso lhe importava: “(...) E se pois me estimas e me queres ver contente, mesmo na presença da morte, faze porque me conste que vivas tranquila e tratando da educação de nossos filhos" (ANAIS DO ARQUIVO HISTÓRICO DO RIO GRANDE DO SUL, 1978, p. 143-144). E, ainda neste trecho de carta do dia 16 de outubro de 1835:

Acresce a tudo isto termos o compadre José Félix para ir instruindo nas primeiras letras a nossos filhos e fazer-nos companhia, podendo eu, no repouso, melhor desenvolver nossos interesses por não excitar a inveja de ninguém etc. etc., e ficar a cidade à mão para depois nossos filhos seguirem estudos maiores (ANAIS DO ARQUIVO HISTÓRICO DO RIO GRANDE DO SUL, 1978, p. 162-165).

Estas cartas nos dão a ideia de que havia participação na preparação para a vida adulta dos filhos, assim como uma grande preocupação com o planejamento do futuro destes, pois a educação podia ser um importante elemento na vida desta elite sul-riograndense, já que possibilitava a ascensão sócio-profissional e até mesmo política. Além disso, as transformações institucionais e jurídicas ocorridas no século XIX, que ampliaram as posições políticas e econômicas, fizeram com que a elite se reorganizasse para dedicarse a vários campos e atividades (alguns seguiram as mesmas atividades dos pais) e determinas competências passaram a ser requisito básico para a atuação em diversos campos. Além disso, a instrução poderia estar ligada à concepção de formação dos futuros cidadãos sul-rio-grandenses. Em artigo ao jornal OPovo, Domingos José de Almeida, defensor da educação pública, escreveu:

Para formar um homem eu prefiro a educação doméstica; para formar um Povo eu prefiro a pública. O aluno do Magistrado, e da Lei não será nunca um Emilio; porém sem a educação do Magistrado e da lei, haverá um Emilio, uma Cidade, mas não haverá cidadãos ( $O$ Povo, 06/05/1840, $\mathrm{N}^{\circ}$. 156, Vol. IV, p.3).

${ }^{6}$ Luís era um dos outros filhos de Bernardina e Domingos. 
A educação poderia ser um importante meio para a divulgação dos ideais da elite farroupilha. Através dela poderiam se obter bons servidores da pátria sul-rio-grandense, formar jovens de virtudes e espírito guerreiro, lhes ensinar o heroísmo e o valor de encarar os perigos, privações, morigeração, constância e ainda o cumprimento das leis. Em discurso feito na abertura da aula do ensino mútuo, impresso pelo jornal $O$ Povo, o professor Luiz Carlos d'Oliveira dirigiu-se aos alunos da seguinte forma:

(...) Vedes um Governo sábio e bem intencionado, que apesar dos estorvos e das peas que lhe impõem a injusta guerra que nos fazem, promove nossa ventura subministrando-vos os meios de alargar vossa razão, fazendo-vos conhecer a Arte da Escritura, pela qual conseguireis o estudo das ciências úteis a humanidade, as luminosas idéias de todos os sábios do mundo, e a santidade e pureza da moral evangélica. Esta arte que é o órgão e o arremedo da Eternidade, enfrea nossas desordenadas paixões, insuflando-nos o temor da pública execração, e serve de núcleo a virtude e ao heroísmo, levando com espanto, admiração e respeito nossas boas ações a posteridade (...). É seguindo seus ditames (do método Lancaster) que me proponho a ensinarvos, esperando que com vossa assídua aplicação secundarei meus esforços para podermos ver realizadas as esperanças do Patriótico Governo, que nos rege, e cimentados os verdadeiros princípios sobre os quais se escoram o grande Edifício de nossa Regeneração Política, que só reclama Moral, e Ilustração (O Povo, 16/10/1839. №.110, Vol.VIII, p.3).

Entre outra empreitada da vida de um homem estava a escolha de um cônjuge e de sua carreira, para isso, ele deveria contar com o auxílio do pai. Cabia a este não somente o empenho de ajudar o filho na escolha de um par, como também havia a obrigação de orientar o casamento de suas filhas. Contudo, era sempre sensato ao genitor não abusar de sua posição e direcionar os rebentos a carreiras e casamentos inadequados. Além disso, a persuasão, às vezes, poderia ser uma arma muito melhor que a coerção. O pai devia levar em consideração a inclinação dos filhos para certos tipos de trabalhos. Como lembra Renata Ago:

Essa tarefa de autocontrole por parte dos adultos incluía também a necessidade de não abusar da posição dos filhos, direcionando-os para "estados" ou "carreiras" não adequados a eles, com o único fim de satisfazer o próprio orgulho ou a própria avidez por riquezas (AGO, 1996, p.301).

Dentro das relações de paternidade, também poderia haver afinidades privilegiadas que beneficiavam um ou outro filho, até mesmo nas questões de afetividade. Como as leis para herdar exigiam equidade na partilha dos bens entre os filhos, algumas vezes os pais poderiam mostrar sua preferência pelo que deixava a algum dos herdeiros. A distribuição poderia revelar, assim, a predileção por um ou outro filho. Mesmo nas correspondências pode-se achar um pouco disso. Em carta trocada entre Domingos José de Almeida e sua 
esposa Bernardina, ele nos revela o seguinte: "Estimarei que nossos filhos não periguem, principalmente Bruto, cuja perda me poria em desespero" (ANAIS DO ARQUIVO HISTÓRICO DO RIO GRANDE DO SUL, 1978, p. 204). E mais uma vez: “(...) Bruto e Custódia, cuidado com eles" (ANAIS DO ARQUIVO HISTÓRICO DO RIO GRANDE DO SUL, 1978, p. 207). As filhas também eram lembradas nas cartas, de forma tão amorosa quanto os filhos. Antônio Vicente da Fontoura fez rimas para serem cantadas por suas meninas, as quais deixava transparecer verdadeira adoração:

(...) hoje mesmo sonhei que tinha visto a Lindoca, que a tinha abraçado, e a Antoninha também, com a carinha suja, pegando no Bentinho. Ah, não faças as pobrezinhas rezar muito"./ "Dá mil beijos no nosso Bentinho, um abraço a todas as filhinhas e notícias da minha Lindoca, se está mui crescida (DIÁRIO DE ANTÔNIO VICENTE DA FONTOURA, 1984, p. 22 e 40).

E ainda:

A caixinha de tintas vai para a Lindoca porque me parece que é afeiçoada ao desenho; um lenço de seda verde com as armas republicanas é para Bindunga que é a mais faceira; as minhas chilenas de prata são para a Antoninha porque é a que trabalha mais, e deve desde já ir fazendo sua acumulação de dote; o avô que lhe faça colheres e ela que guarde; e para minha Gabriela remeto o caiapim, que sempre tem sido minha esteira de cama (DIÁRIO DE ANTÔNIO VICENTE DA FONTOURA, 1984, p. 144).

Como aos meninos, era importante também, desde cedo, ensinar às meninas o enfrentamento as adversidades como o apoio aos homens da família. A sociedade sul-riograndense do século XIX foi marcada por uma ideia muito forte de guerra e masculinidade e as mulheres que pertenciam à elite farroupilha, por sua vez seriam filhas, esposas e mães de indivíduos que passaram e passariam ainda por muitos combates. Delas esperava-se um comportamento que se ajustasse à vida desses homens e tanto suas mães como seus pais eram um exemplo a ser seguido e procurado.

\section{Conclusão}

Ser pai podia ser uma tarefa bem difícil. Sua figura devia ser rodeada pela concepção de respeito, honra, virilidade e competência. Cabia aos pais o acúmulo de bens materiais e simbólicos a serem repassados aos filhos e, algumas vezes, isto era utilizado como uma justificativa para a guerra; ela servia para salvaguardar estes bens. Ele, o pai, atuava no âmbito público, mas também no doméstico, uma vez que as decisões fundamentais do núcleo familiar passavam por ele. Dessa forma, a vida e o desenvolvimento dos descendentes faziam 
parte de suas preocupações, pois além do afeto, havia a intenção de perpetuação. Eram eles que dariam continuidade ao nome do pai. Assim, não é de se espantar que os filhos fossem uma questão frequente nos assuntos trocados nas cartas, já que havia uma preocupação genuína com a vida destes e com algumas questões que envolviam o seu cotidiano.

As formas de classificação dos indivíduos na família eram formas sociais relativas a um grupo particular e determinadas pela sociedade. Para isso, deveria haver um consenso social sobre estes lugares na família. Em outras palavras, a posição das pessoas no grupo familiar dependia profundamente do conhecimento e do reconhecimento social desta posição. O que apresento aqui é de certa forma um ponto de vista dominante, no qual mostro a ideia que estes formavam de si próprios, influenciados pelo que o mundo social lhe atribuía para o seu “ser" e o "dever ser". Contudo, esta imagem de si mesmo não deixa de ser legítima.

\section{Fontes impressas}

ANAIS DO ARQUIVO HISTÓRICO DO RIO GRANDE DO SUL, (AAHRS - Coleção Varela), 17 volumes. Porto Alegre: Arquivo Histórico do Rio Grande do Sul.

DIÁRIO DE ANTÔNIO VICENTE DA FONTOURA. Porto Alegre: Sulina/ Martins, Caxias do Sul: EDUCS, 1984.

COLETÂNEA DE DOCUMENTOS DE BENTO GONÇALVES DA SILVA - 1835/1845. Arquivo Histórico do Rio Grande do Sul. Porto Alegre: Comissão Executiva do Sesquicentenário da Revolução Farroupilha, Subcomissão de Publicações e Concursos, 1985.

Jornal O Povo. Museu de Comunicação José Hipólito da Costa.

\section{Fontes documentais}

ORDENAÇÕES FILIPINAS. Livro 04, Tit. 80-107. Disponível em http: //www.uc.pt/ihti/proj/filipinas/ordenacoes.htm.

\section{Referências bibliográficas}

AGO, Renata. Jovens Nobres na Era do Absolutismo: autoritarismo paterno e liberdade. In: LEVI, Giovanni; SCHMITT, Jean-Claude (org.). História dos Jovens: da Antiguidade à Era Moderna. Vol.1. Tradução Claudio Marcondes, Nilson Moulin, Paulo Neves. São Paulo: Companhia das Letras, 1996, p. 325-369.

ALMEIDA, Marino Josetti. General Bento Gonçalves. In: Revista do Instituto Histórico e Geográfico do Rio Grande do Sul. Porto Alegre: Oficinas Gráficas da Imprensa Oficial, Ano XXVII, I a IV trimestre de 1947, n. 105-108, p. 31-46. 
ANDERSON, Michael. Elementos para a História da Família Ocidental (1500-1914). Lisboa: Editoral Querco, 1980.

ANDRADE, Mateus de Souza, et al. Cadernos de Graduação - Ciências Humanas e Sociais, Aracaju, out. 2012, v. 1, n.14, p. 175-181.

ANTUNES, De Paranhos. Antônio Vicente da Fontoura: o Embaixador dos Farrapos. Porto Alegre: Livraria do Globo, 1935.

BARBOSA, Carla A.S. A casa e suas virtudes: relações familiares e a elite farroupilha (RS, 1835-1845). 2009. Dissertação (Mestrado em História) - Unisinos,São Leopoldo, 2009.

BOURDIEU, Pierre. O poder simbólico. Tradução Fernando Tomaz. 11 ed. Rio de Janeiro: Bertrand Brasil, 2007.

BRÜGGER, Sílvia Maria Jardim. Minas Patriarcal - Família e Sociedade (São João Del Rei, séculos XVIII e XIX). 2002. Tese (Doutorado) - Universidade Federal Fluminense, Niterói, 2002.

BURGUIÈRE, André (org.). História da Família. Vol.1. Tradução Ana Santos da Silva e João Silva Saraiva. Lisboa: Terramar, 1996.

CUNHA, Zeferino José da. Apontamentos para a história da Revolução de 1835: Biographia de Domingos José de Almeida. Pelotas: Typographia da Livraria Americana, 1902.

DELUMEAU, Jean; ROCHE, Daniel (Dirs.). Histoire des pères et de la paternité. Paris: Larousse, 2000.

FABRÍCIO, José de Araújo. A descendência de Bento Gonçalves da Silva. Porto Alegre: Martins Livreiro, 1986.

FLORES, Moacyr. Revolução Farroupilha. Porto Alegre: Martins Livreiro, 1984.

GUAZZELli, César Augusto Barcellos. O Horizonte da Província: a República Riograndense e os caudilhos do Rio da Prata (1835-1845). 1998. Tese (Doutorado em História) - UFRJ, Rio de Janeiro, 1998.

GUIMARÃES, João Pinto da Fonseca; FELIZARDO, Jorge Godofredo. Genealogia Riograndense. Vol. I. Porto Alegre: Globo, 1937.

KUZNESOF, Elizabeth A. A Família na Sociedade Brasileira: Parentesco, Clientelismo e Estrutura Social (São Paulo, 1700-1980). In: SAMARA, Eni de Mesquita (org.). Família e Grupos de Convívio. Revista Brasileira de História. São Paulo: ANPUH/ Marco Zero, vol.09, n.17, setembro de 1988/ fevereiro de 1989, pp. 37-63.

LÉVI-STRAUSS, Claude. As estruturas elementares do parentesco. 3 ed. Tradução Mariano Ferreira. Petrópolis: Vozes, 1982.

MACEDO, Francisco Riopardense de. Bento Gonçalves. 2 ed. Porto Alegre: IEL, 1996. 
MARAVALL, José Antonio. Poder, honor y élites en siglo XVII. Madrid: Siglo Veintiuno Editores, 1989.

MAUSS, Marcel. Ensaio sobre a Dádiva. Forma e razão da troca nas sociedades arcaicas. In: . Sociologia e Antropologia. Vol.II. São Paulo: EDUSP, 1974.

MONSMA, II $^{\mathbf{0}}$ Encontro da Rede Internacional Marc Bloch de estudos comparados em história - Europa / América Latina, 2008.

MONTEIRO, Lorena. Sociedade e Cultura. Goiânia, v. 12, n. 1, p. 25-32, jan./jun. 2009.

NEVES, Ilka. Domingos José de Almeida e sua descendência. Porto Alegre: EDIGAL, 1987.

PESAVENTO, Sandra Jatahy. A Revolução Farroupilha. São Paulo: Brasiliense, 1990.

PRIORE, Mary Del; AMANTINO, Marcia (Orgs.). História dos homens no Brasil. São Paulo: Editora Unesp, 2013.

REICHARDT, H. Canabarro. Bento Gonçalves. Porto Alegre: Globo, 1932.

ROHDEN, Fabíola. Honra e família em algumas visões clássicas da formação nacional. Revista Brasileira de Informação Bibliográfica em Ciências Sociais. Rio de Janeiro, n.48, $2^{\circ}$ semestre de 1999, pp.69-89.

ROSA, Othelo. Vultos da Epopéia Farroupilha. Porto Alegre: Globo, 1935.

SAMPAIO, Fernando G. Bento Gonçalves: mito e história. Porto Alegre: Martins Livreiro, 1984.

SARACENO, Chiara. Sociologia da Família. Tradução M.F. Gonçalves de Azevedo. Lisboa: Editorial Estampa, 1997.

SPALDING, Walter. A epopéia farroupilha. Rio de Janeiro: Biblioteca do Exército, 1963.

. Construtores do Rio Grande do Sul. I Volume. Porto Alegre: Editora Sulina, 1969.

Construtores do Rio Grande. III Volume. Porto Alegre: Editora Sulina, 1973.

STEWART, Frank Henderson. Honor. Chicago: The University of Chicago Press, 1994.

VARGAS, Jonas. Anais do XXVI Simpósio Nacional de História - ANPUH. São Paulo, julho, 2011. 